Special issue of the 2nd International Conference on Computational and Experimental Science and Engineering (ICCESEN 2015)

\title{
Computed Tomography Routine Examinations and the Related Risk of Cancer
}

\author{
Ü. KARA ${ }^{a, *}$, H.O. TEKIN ${ }^{b}$ AND I. AKKURT ${ }^{c}$ \\ ${ }^{a}$ Suleyman Demirel University, Vocational School of Healt Services, Isparta, Turkey \\ ${ }^{b}$ Uskudar University, Vocational School of Healt Services, Istanbul, Turkey \\ ${ }^{c}$ Suleyman Demirel University, Physics Department, Isparta, Turkey
}

\begin{abstract}
Computed tomography is an imaging process that uses x-ray equipment to create detailed scans, of areas inside the body. A picture created during computed tomography process shows the organs, bones, and other tissues in a thin "slice" of the body. Computed tomography is used in cancer diagnosis in many different ways to detect abnormal growths, helps to diagnose the presence of a tumor, provides information about the stage of cancer, determines exactly where to perform a biopsy procedure. The x-rays, gantry around the head, chest or another body part, helps to make a three-dimensional image that is much more detailed than pictures from other x-ray machines. Computed tomography imaging involves the use of x-rays, which are a form of ionizing radiation. Exposure to ionizing radiation is known to increase the risk of cancer. The aim of this study was to assess the radiation exposure received during computed tomography in a representative sample of patients.
\end{abstract}

DOI: 10.12693/APhysPolA.130.409

PACS/topics: 87.56.-v, 87.55.Qr

\section{Introduction}

Radiation is widely used in a variety of fields and especially in medical centers. It is known that clinical radiation is necessary for diagnosis. Radiology, nuclear medicine, radiation oncology use radiation for diagnosis and treatment. Radiology department often uses radiation for diagnosis. Computed tomography is a medical imaging technology in radiology department which is used for screening and diagnosis of medical condition. It involves taking numerous x-ray images of a body area or organ and these images are reconstituted into computergenerated pictures [1]. Computed tomography images of organs, bones, soft tissues and blood vessels are typically provided in greater detail than in traditional x-ray machines like that of Rontgen.

\section{Materials and methods}

In this study, we have been working at Radiology Department in a hospital which uses computed tomography medical imaging unit (see Fig. 1). We have measured
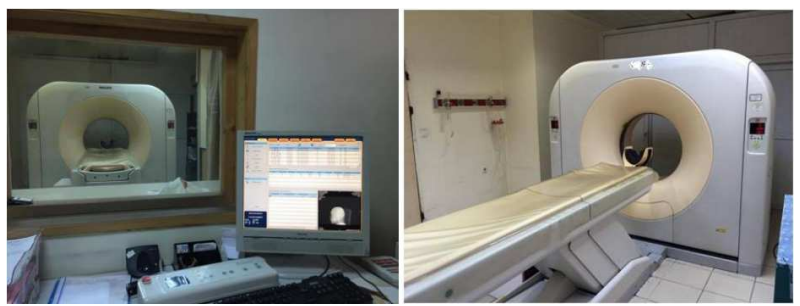

Fig. 1. Used computed tomography.

\footnotetext{
*corresponding author; e-mail: umitkara@sdu.edu.tr
}

radiation doses of radiology patients subjected to computed tomography. We have recorded radiation factors and radiation doses during routine works on radiology with computed tomography.

TABLE I

Conversion factor for calculations of effective doses [3].

\begin{tabular}{c|c|c|c|c|c}
\hline \hline Body region & 0 & 1 & 5 & 10 & Adult \\
& year-old & $\begin{array}{c}1 \\
\text { year-old }\end{array}$ & $\begin{array}{c}\text { years-old } \\
\text { years-old }\end{array}$ & \\
\hline Head and neck & 0.013 & 0.0085 & 0.0057 & 0.0045 & 0.0031 \\
Head & 0.011 & 0.0067 & 0.0040 & 0.0032 & 0.0021 \\
Neck & 0.017 & 0.012 & 0.011 & 0.0079 & 0.0059 \\
Chest & 0.039 & 0.026 & 0.018 & 0.013 & 0.014 \\
Abdomen & 0.049 & 0.030 & 0.020 & 0.015 & 0.015 \\
Trunk & 0.044 & 0.028 & 0.019 & 0.014 & 0.015
\end{tabular}

When we carried out the measurements, the patients and the medical staff were in their routine locations. Routine scanning protocols were considered. This routine protocols are computed tomography scanning of the abdomen, head, thorax, cervical and pelvis. The IAEA definitions were adopted for the dosimetric quantities expressed in terms of kerma [2]. The weighted air kerma index $C_{\mathrm{w}}$ (see Eq. (1)) has the objective of measuring the air kerma index within the phantoms; the volumetric air kerma index $C_{\mathrm{vol}}$ (Eq. (2)) provides the estimate of the dose in a single section; the air kerma-length product $P_{\mathrm{KL}, \mathrm{CT}}$ (Eq. (3)) provides the air kerma in the whole irradiated area during the acquisition of the tomographic image. We have also adopted the concept of effective dose estimated from $P_{\mathrm{KL}, \mathrm{CT}}$ as a function of a conversion factor $k$ (Eq. (4), Table I), depending only on the irradiated body region [3]. The effective dose is basically found from the product of the dose length product and the conversion factor. 


$$
\begin{aligned}
& C_{\mathrm{w}}=1 / 3\left(C_{\mathrm{PMMA}, 100, \mathrm{C}}+2 C_{\mathrm{PMMA}, 100, \mathrm{P}}\right), \\
& C_{\mathrm{vol}}=C_{w} / \text { pitch, } \\
& P_{\mathrm{KL}, \mathrm{CT}}=\sum N c_{\mathrm{Vol}} l_{j} P_{I t} \\
& E=k P_{\mathrm{KL}, \mathrm{CT}} \\
& E=\mathrm{DLP} k
\end{aligned}
$$

\section{Results}

CDTI stands for computed tomography dose index. It is a standardized measure of radiation dose output of a CT scanner which allows the user to compare radiation output of different CT scanners. $\mathrm{CTDI}_{\mathrm{vol}}$ is obtained by dividing $\mathrm{CTDI}_{\mathrm{w}}$ by pitch factor. DLP stands for dose length product. DLP is the product of the $\mathrm{CTDI}_{\mathrm{vol}}$ and the scan length for a group of scans (Table III). This number can be summed over the entire examination to give an estimate of the total dose. The value is expressed in $\mathrm{mGy} \mathrm{cm}$. Pitch is defined as the ratio of the table travel per rotation to the total nominal beam width $[4,5]$. Table II shows the com-

TABLE II

Computed tomography radiation factors for patients and radiation measurement points.

\begin{tabular}{c|c|c|c|c}
\hline \hline Age & Gender & Region of body & mAs (helical) & $\mathrm{kV}$ (helical) \\
\hline 65 & $\mathrm{M}$ & Abdomen & 249 & 120 \\
60 & $\mathrm{~F}$ & Abdomen & 249 & 120 \\
65 & $\mathrm{M}$ & Head & 298 & 120 \\
64 & $\mathrm{~F}$ & Head & 298 & 120 \\
69 & $\mathrm{M}$ & Thorax & 249 & 120 \\
67 & $\mathrm{~F}$ & Throax & 219 & 120 \\
52 & $\mathrm{M}$ & Cervical & 298 & 120 \\
75 & $\mathrm{~F}$ & Cervical & 249 & 120 \\
61 & $\mathrm{M}$ & Pelvis & 254 & 120 \\
48 & $\mathrm{~F}$ & Pelvis & 254 & 120
\end{tabular}

(a)

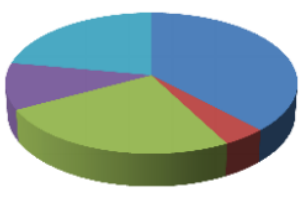

Abdomen

Head
Thorax
Cervical
Pelvis

Fig. 2. Body and gender specific effective doses of computed tomography, (a) male, (b) female.

puted tomography protocols and patients radiation factors and radiation measurement points. Figure 2 shows organ doses, effective doses, gender and risk indices in adult computed tomography. Figures 3 and 4 show comparison between different categories of patients in terms of organ doses, effective doses and DLP in five examined categories abdomen, head, thorax, cervical and pelvis. The quantitative differences were tabulated. The coefficient of variation for effective doses is displayed above the bars for each examination.

TABLE III

Ct patients factors and the volume CT dose index $\left(\mathrm{CTDI}_{\mathrm{vol}}\right)$ and dose length product (DLP).

\begin{tabular}{c|c|c|c|c}
\hline \hline Age & Gender & $\begin{array}{c}\text { CTD }_{\text {vol }} \\
\text { [mGy] (helical) }\end{array}$ & $\begin{array}{c}\text { DLP [mGy cm] } \\
\text { (helical) }\end{array}$ & $\begin{array}{c}\text { Effective } \\
\text { dose [mSv] }\end{array}$ \\
\hline 65 & $\mathrm{M}$ & 22.28 & 994.95 & 14.9 \\
60 & $\mathrm{~F}$ & 24.57 & 901.33 & 13.5 \\
65 & $\mathrm{M}$ & 45.61 & 841.25 & 1.7 \\
64 & $\mathrm{~F}$ & 48.33 & 823.56 & 1.7 \\
69 & $\mathrm{M}$ & 22.34 & 702.78 & 9.8 \\
67 & $\mathrm{~F}$ & 19.66 & 621.16 & 8.6 \\
52 & $\mathrm{M}$ & 56.19 & 720.52 & 4.2 \\
75 & $\mathrm{~F}$ & 42.61 & 743.28 & 4.3 \\
61 & $\mathrm{M}$ & 22.8 & 584.25 & 8.7 \\
48 & $\mathrm{~F}$ & 22.8 & 705.07 & 10.5
\end{tabular}

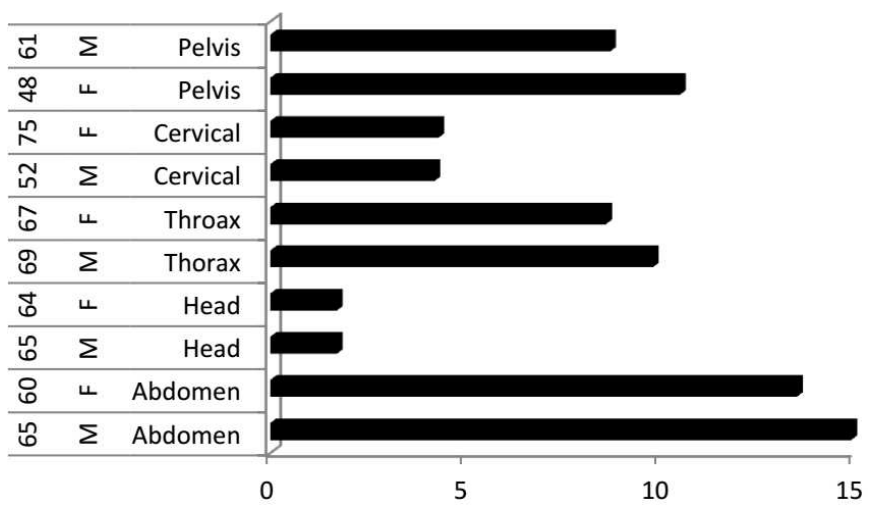

Fig. 3. Body-, age- and gender-specific effective doses of computed tomography (male-female).

\section{Discussion}

Computed tomography scan is an important method of diagnostics. Computed tomography units have become safer over the time, but due to their increased usage and frequency of scans, the radiation exposure is an important public health concern. In most circumstances, the risk to an individual patient of developing a malignant tumor caused by the computed tomography is low and acceptable compared to the substantial benefit, although there is a large uncertainty in risk estimates at these dose levels. Computed tomography usage has increased over the past several years. Computed tomography examinations have also increased, in part due to the increased speed of image acquisition allowing vascular, cardiac, and multiphase examinations, all associated with higher doses. Thus, greater use of computed tomography has resulted in a concurrent increase in the medical exposure to ionizing radiation $[6,7]$. 


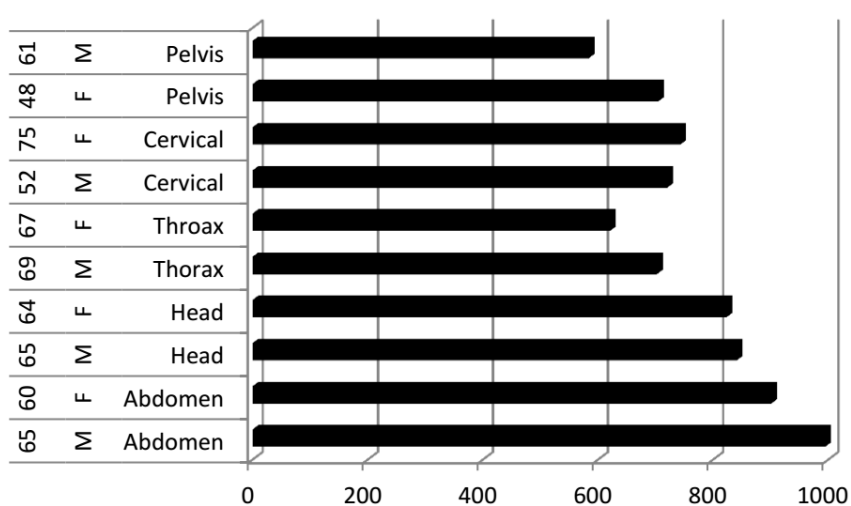

Fig. 4. Body-, age- and gender-specific DLP of computed tomography (male-female).

\section{Conclusions}

CT delivers much higher radiation doses than do conventional x-ray imaging. Even though the risk to an individual patient may be small, the increasingly large number of people exposed, coupled with the increasingly high exposure per examination, could translate into many cases of cancer resulting directly from the radiation exposure from computed tomography.

\section{References}

[1] Whole body screening using MRI or CT technology, Health Canada, Ottawa 2003.

[2] International Atomic Energy Agency, Dosimetry in diagnostic radiology: an international code of practice, Technical Reports Series no. 457, Vienna 2007.

[3] American Association of Physicists in Medicine, The measurement, reporting, and management of radiation dose in CT, AAPM Report No. 96, College Park 2008.

[4] C.H. McCollough, F.E. Zink, Med. Phys. 26, 2223 (1999).

[5] International Electrotechnical Commission (IEC), Medical Electrical Equipment, Particular requirements for the safety of $x$-ray equipment for computed tomography, No. 60601-2-44. Ed. 2.1, Geneva 2002.

[6] E.S. Amis, P.F. Butler, K.E. Applegate, S.B. Birnbaum, L.F. Brateman, J.M. Hevezi, F.A. Mettler, R.L. Morin, M.J. Pentecost, G.G. Smith, K.J. Strauss, R.K. Zeman, J. Am. College Radiol. 4, 272 (2007).

[7] National Council on Radiation Protection and Measurements, Ionizing Radiation Exposure of the Population of the United States, NCRP report 160, www . ncrponline.org/, accessed October 7, 2009. 